\title{
An Overview of the Evolution of Porous Silicon Material: A Review
}

\author{
Ghazwan Ghazi Ali ${ }^{*}$, Marwan Hafeedh Younus², Ivan B. Karomi ${ }^{3}$ \\ ${ }^{1 * 2,3}$ Department of Physics, College of Education for Pure Sciences, University of Mosul, Mosul, Iraq \\ E-mail: ${ }^{1 *}$ dr.ghazwan39@uomosul.edu.iq, ${ }^{2}$ marwan.hafed@uomosul.edu.iq, ${ }^{3}$ ivanbahnam@uomosul.edu.iq
}

(Received September 14, 2020; Accepted November 22, 2020; Available online June 01, 2021)

DOI: 10.33899/edusj.2020.128341.1111, () 2021, College of Education for Pure Science, University of Mosul.

This is an open access article under the CC BY 4.0 license (http://creativecommons.org/licenses/by/4.0/).

\begin{abstract}
Recently, the properties and applications of porous has become the main subject of a vast numbers of books and review articles. Porous silicon has demonstrated significant versatility and promise for a wide range of optoelectronic applications due to its large surface area and intense photoluminescence at room temperature. In this review, we describe the fabrication techniques and experimental improvements made towards porous silicon (PSi) and we provide a full picture of realization and characterization of this material. We also highlight its important chemical, structure and surface properties. Additionally, we will introduced the techniques that have been used to characterize porouse silicon, including Fourier transform infrared spectroscopy, X-ray diffraction measurements, atomic force microscope images (AFM) and a scanning probe microscope (SEM). Moreover, the effect of the current density and etching time are also documented in this review. In summary, porous silicon has undergone vast improvement in both fabrication and characterization methods, which makes it an attractive modern material.
\end{abstract}

Keywords: Porous silicon, fabrication methods, optical properties, electrical properties.

$$
\text { نظرة عامة في تطور مادة السيليكون المسامي: مراجعة مقالة }
$$

\footnotetext{
الملخص

اصبح السيليكون المسامي في السنوات الاخيرة الموضوع الرئيسي في عدد كبير من الكتب و مقالات المراجعة. اظهر

السليكون المسامي تتوعا كبيرا واهمية فريدة من نوعها لمجموعة كبيرة من التطبيقات الالكتروضوئية بفضل المساحة السطحية

الكبيرة والاستضاءة الضوئية الواسعة عند درجة حرارة الغرفة. في هذه المقالة سوف نقوم بعرض شامل لتقنيات التصنيع والتحسينات

التجريبية التي تم اجراؤها على السليكون المسامي PSi ونعرض صورة كاملة لدراسة لتوصيف هذه المادة ـ سوف نقوم ايضا بتسيلط

الضوء على خصائصده المهمة، والتي تشمل الخصائص الكيميائية ,الخصائص التركيبية بالاضافة الى الخصائص السطحية. علاوة

على ذلك، سنقوم بعرض التقنيات التي تم استخدامها في فحص و اختبار عينات السيليكون المسامي والتي تتضمن التحليل الطيفي

للأشعة تحت الحمراء (تحويلات فورير) وقياسات حيود الاشعة السينية (X-ray) وصور مجهر القوة الذرية (AFM ) ومجهر
} 


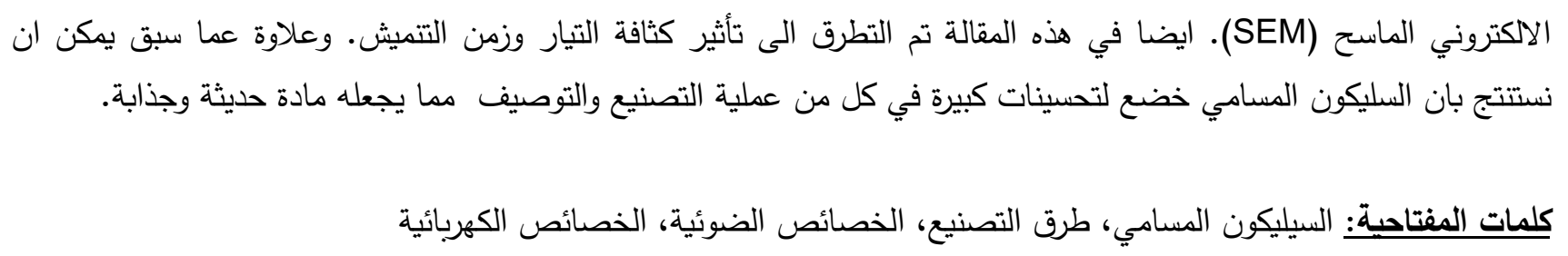

\section{Introduction}

Porous silicon was discovered in 1956 by Uhlir [1] using electro-polishing experiments which were performed on the substrate of silicon wafer using an electrolyte solution includeing hydrofluoric acid (HF). From 1970 to 1980, interest in porous silicon rapidly increased because of its high surface area, which was useful for a model of the crystalline silicon surface in spectroscopic studies. The study of the photoluminescence efficiency (PL) at room temperature introduced by Canham in 1990 [2] at the red region $(1.4-2.2 \mathrm{e} \mathrm{V})$ of the porous silicon, which attracted great attention to manufacturers, who commercialized an integrated optical device on silicon. Lehmann and Gosele in 1991 [3] observed that the band gap of non-porous silicon could be modified by the quantum confinement effects. A few years later, multicolour photoluminescence and visible electroluminescence were reported. Since that time, the considerable interest of researchers in this material has constantly grown. Tsai et al. developed the first device of photovoltaic (photodetectors and light emitting diodes) in 1993 [4]. In 1995, porous silicon (PSi) was prepared via electrochemical etching method by Halimaoui et al. [5], the photoemission and X-ray absorption spectroscopy analysis were used to characterise the properties of PSi. Their results showed shifting in the conduction band and valence band of the PS relative to the bands for silicon bulk, this agreement is expected in the model of quantum confinement for the optical properties of PSi. In 1997, Shigyo et al. [6] prepared and studied porous silicon layer (PSL) on p-type silicon with electrochemical etching. They found that the visible photoluminescence intensity increased with decreasing concentration of silicon hydrides $\left(\mathrm{SiH}_{\mathrm{x}}\right)$. In 1997, Smith et al. [7] reported a blue shift in metal/PSi/c-Si structures compared to that of c-Si based photodetectors. Then, the rapid thermal oxidation method was used to develop a high-gain photodetector of PS planar metal-semiconductormetal by Duttagupta in 1998 [8]. Moreover, Coulthard et al. in 2000 [9] prepared PS samples by electrochemical etching and then studied the PL of the PSi samples using a synchrotron as a tuneable excitation source. They exhibited a shift in the luminescence spectrum when the growth conditions changed. Furthermore, the effect of HF concentration mixed with ethanol on PL was investigated by Ohmukai and Collins in 2001[10]. They concluded that the strong PL was produced when the PSi anodized with the electrolyte containing 35 or 40\% HF acid Foll et al. in 2002 [11] showed that photo-generation in heterostructures $(\mathrm{Ni} / \mathrm{PSi} / \mathrm{p}-\mathrm{Si} / \mathrm{Ni})$ occurs in both regions of a thin PSL and Psi base. Jarimaviciute et al. in 2003 [12] built and tested equipment for the electrochemical etching of silicon in hydrofluoric acid as an electrolyte. Their study revealed that current density controls the geometry of the pores. In 2004, Gaburro et al. [13] fabricated a gas-sensing device based on PSi, these etched substrates were prepared to form a PSi layer by anodization. Pap et al. in 2005 [14] found that the surface roughness of oxidized PSi layers increases with oxidation between $200-400{ }^{\circ} \mathrm{C}$ and decreases between $600-800{ }^{\circ} \mathrm{C}$. Nichiporuk et al. in 2006 [15] analysed the passivation of the front surface of a p-Si interdigitated back contact solar cell (IBC) by a thin PS layer. An improvement in the efficiency up to $87 \%$ was observed after a PS layer formed on the front surface of the IBC cell. Chaoui et al. in 2007[16] studied the fabrication of photo detectors using metal-PSi with different geometries of the PSi layer. They found that the significant response from the spectra can be determined based on the geometrical design of these devices. In addition, they showed that the maximum response was measured when the pair of generated electron-hole cross a short path from the point to the metallic contact where it is collected. Kanungo and Rumpf in 2009 [17], 
observed that the solution of palladium chloride $\left(\mathrm{PdCl}_{2}\right)$ with chemically modifying PSi surface can be used to achieve a stable low resistance aluminium (Al) which contact to PS. Granitzer et al. in 2010 [18] they found that the produced silicon nanocrystals size can be controlled in two steps:- the first step, is to use the rapid thermal annealing technique for rapid anneling at $1000^{\circ} \mathrm{C}$ in nitrogen ambient, and second step, is to use the radio frequency magnetron for rapid oxidation at $600-800^{\circ} \mathrm{C}$. Jian Feng et al. in 2016 [19] fabricated porous silicon microcavities (PSM) optical crystals to design an optical sensor for the detection of environmental pollutants, including volatile organic vapours. The anodization technique was used by Behzad et al. in 2017 [20] to prepare different layers of PSi using different etching times and fixed current density. They found that band gap value increased by raising the porosity. In 2018, Ghazwan et al. [21] prepared PSi by electrochemical etching technique and then Zinc oxide layers were deposited on porous silicon by the CVD method. The physical properties indicate that $\mathrm{ZnO}$ shows a good homogenous layer. Ghazwan et al. in 2019 [22] fabricated PSi (P-type) with electrochemical etching and irradiation with neutrons. They showed that the optical transmittance increases with etching time. Furthermore, the percentage of porosity decreased after irradiation. Finally, Ghazwan et al. in 2020 [23] prepared nanoporous silicon by electrochemical etching method of various etching times and exposure to neutron flux. They found that an increase in porous size with increasing etching time, and the diameter is larger after irradiation.

\section{Experimental procedure of PSi}

\section{a. Electrochemical etching}

Electrochemical etching (anodization) is the most common technique used to form PSi on a doped Si wafer in an aqueous/ethanolic HF electrolytic solution. A schematic of the PSi formation process in this technique is shown in Figure (1). The Si surface contacted at the down is in contact with concentration of HF solution. After voltage is applied between the Si wafer, the pore growth starts on the silicon surface.

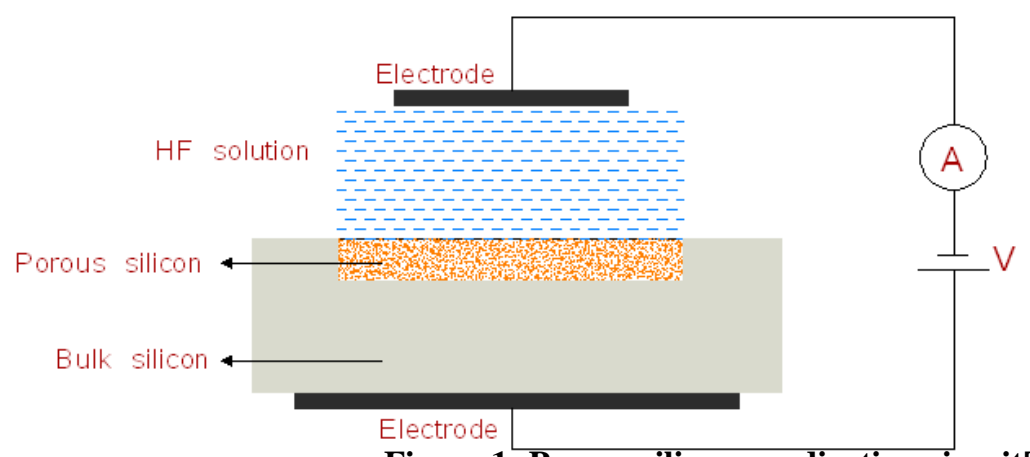

Figure 1: Porous silicon anodization circuit[24]

\section{b. Photochemical etching}

The silicon surface is saturated by hydrogen when HF solution is immersed in $\mathrm{Si}$ wafer due to the interaction between $F^{-}$and $\mathrm{Si}$ bonds. Once the $\mathrm{Si}$ wafer is illuminated by light, electron-holes are generated as a result of light absorption within the wafer. The holes are formed to the Si wafer by the internal field, and hence a depletion layer is created at the irradiated area. The generated holes then help to substitute fluoride by hydrogen on the silicon wafer. When a silicon atom is dissolved from a flat surface, the surface geometry changes the distribution of the electric field similarly. The photo-generated pores at this location referentially, cause an amplification in the inhomogeneity of the surface. Meanwhile, electrical current flows through the electrolyte, completing the electrical circuit. This current boosts the etching process towards thickness direction. This technique rebuilds the surface with different pores and pillar size distributions. 


\section{c. Stain etching}

The technique of stain etching is a simpler procedure than anodic etching. Stain etching requires the silicon substrate to be immersed in hydrofluoric acid, nitric acid, or a water-based etchant. The holes needed for silicon dissolution are generated by reacting between the nitric acid and hydrofluoric acid. However, this method is unique because it gives a PSL with lower photo efficiency, and is hence less homogenous.

\section{d. Photo electrochemical etching}

Photo electrochemical etching (PECE) is an important method in manufacturing PSi material because of its appropriateness for etching n-type and p-type silicon in HF and also because it uses two etching processes (i.e. electrochemical and photochemical). Juhasz and Thonissen, demonstrated that during the formation process, the PSi surface makes significant changes in the structure under illumination. Furthermore, nanoporous silicon covers the silicon layer with different scale of pores [25].

\subsection{Mechanism for pore formation in PSi}

The key point in the reaction at the Si-electrolyte is the reduction of $\mathrm{H}^{+}$to $\mathrm{H}_{2}$. Nevertheless, the $\mathrm{Si}$ wafer dissolves under anodic polarization. Although the theory of the Si dissolution mechanism within the anodization process has not quite been comprehended yet, it is believed that holes are required not only for electro-polishing but also for pore formation. When provided with anodization process, there is interaction between $\mathrm{Si}$ surface and ${F^{-}}^{-}$ions by the formation of $[\mathrm{SiF} 6]^{2-}$ complex ions, as shown in Figure (2). The reactions are given as [26]

$$
\mathrm{Si}+6 \mathrm{HF} \rightarrow \mathrm{H}_{2} \mathrm{SiF}_{6}+\mathrm{H}_{2}+2 \mathrm{H}^{+}+2 \mathrm{e}^{-}
$$

In the case of electro-polishing:

$$
\mathrm{Si}+6 \mathrm{HF} \rightarrow \mathrm{H}_{2} \mathrm{SiF}_{6}+4 \mathrm{H}^{+}+4 \mathrm{e}^{-}
$$

Description of electrochemical dissolution of silicon
1. In the absence of electron holes, a hydrogen saturated silicon surface is
virtually free from attack by fluoride ions in the HF based electrolyte.

Figure 2 : Anodic dissolution mechanism of Si [27]. 


\subsection{Anodization parameters}

\section{a. Current density}

The current density is a key factor to control the porosity of the PSL during the fabrication process. For example, at high current densities, hole transport overcomes the interaction of the $\mathrm{F}^{-}$ ions . Consequently, the surface of the silicon is filled with pores, and each ion left there is met with a hole. This process is electro-polishing. Furthermore, the chance of holes to reach the Si surface is smaller because of the irregular field of distribution at the surface, so pore growth happens in silicon substrate. The anodic dissolution portion of a typical silicon current-voltage curve is illustrated in Figure (3).

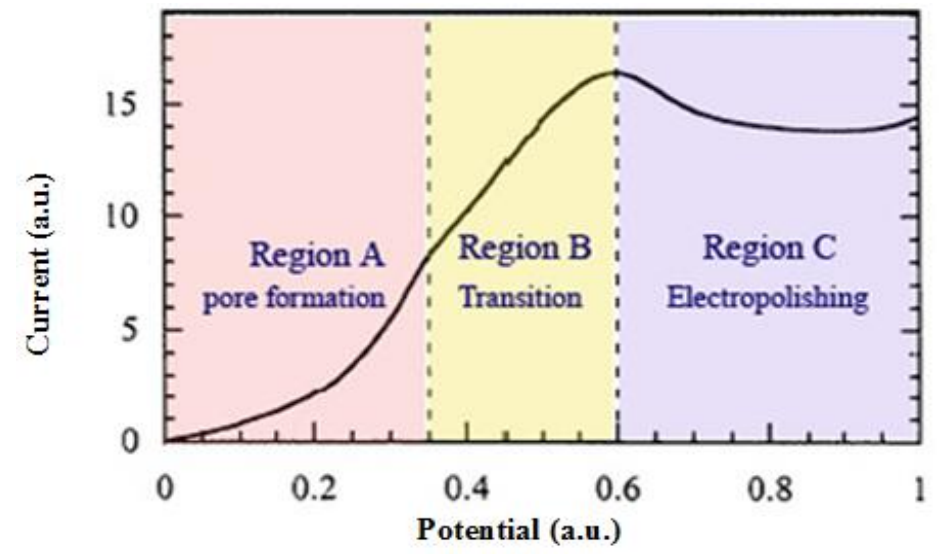

Figure 3:Typical anodic current-voltage relationship for silicon in HF solution[28].

As the current density increases, the silicon dissolution rate increases. Figures (4) (a) and (b) show a linear dependent of PSi porosity and etch rate on current density.
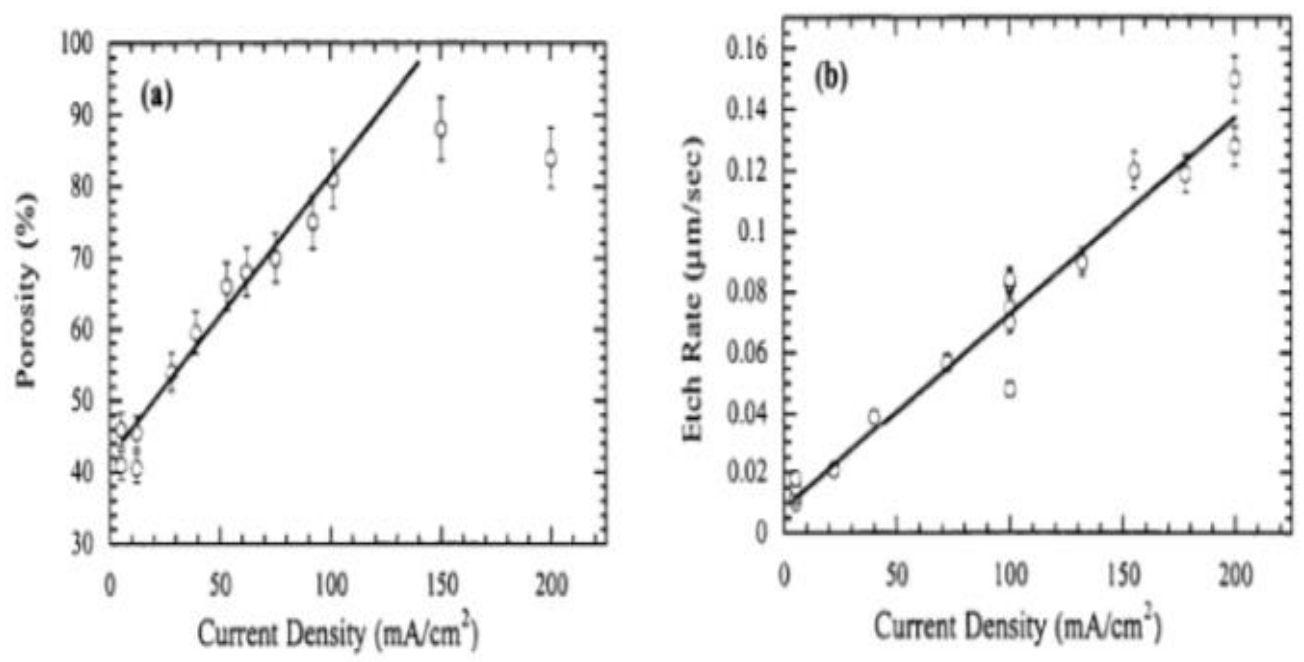

Figure 4: Porous silicon porosity (a) etch rate and (b) depending versus current density for p-

\section{b. Etching time}

type[29]

Etching time is an important variable that can be easily manipulated to dominate the properties of the PSL. In particular, the thickness and porosity of PSL are etching time dependant. Figure (5) plots the thickness of the PSL against anodization time. 


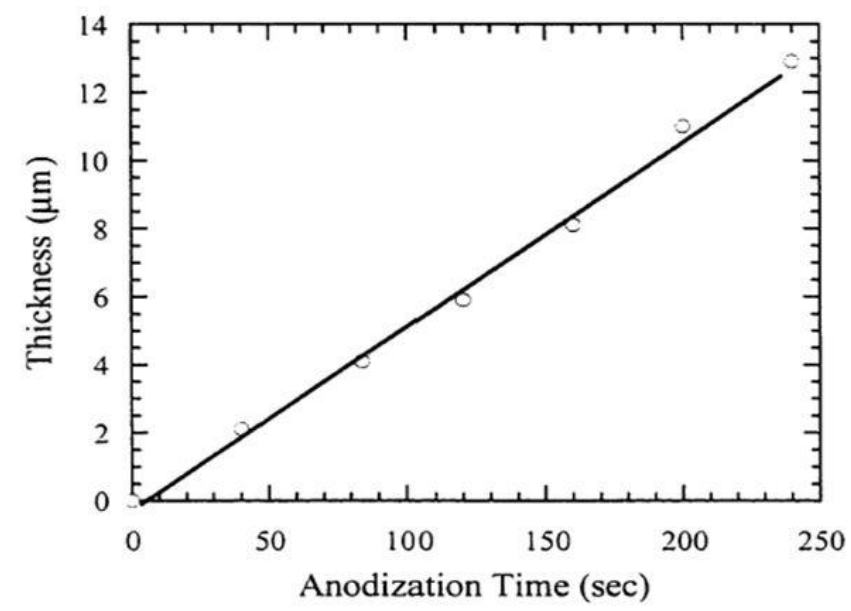

Figure 5 :Thickness versus anodization time p-type $0.01 \Omega$-cm at fixed current $50 \mathrm{~mA} / \mathrm{cm}^{2}$ in $25 \%$ HF concentration electrolyte[30].

\section{c. Hydrofluoric concentration effect}

The composition of the solution plays a basic role in the etching process. When a purely aqueous HF solution is used in PSi formation, hydrogen bubbles are created and stick to the surface of the layer, which causes inhomogeneity. The most popular way to minimize hydrogen gas formation is to add ethanol to the HF electrolyte. In all subsequent formations of PSi, ethanol is always added to the electrolyte. Ethanol decreases the size of the hydrogen bubbles and makes it easier to remove them from the surface. Ethanol can also improve the penetration of the electrolyte solution in the pores . Lower HF concentration reduces the number of fluoride ions during the etching process, thereby increasing the porosity of the PSi up to its maximum value of $100 \%$, which corresponds to the electro-polishing regime. When operating in this low HF concentration regime, it is important to reduce the applied current density otherwise electro-polishing will occur. Using a lower $\mathrm{HF}$ concentration also has the benefit of slowing the etch rate, which is necessary when etching highly doped silicon substrates [31].

\section{Results and Discussion}

\subsection{Chemical properties of PSi}

Fourier Transform Infrared Spectroscopy (FTIR) displays the chemical bonds in a molecule in PSi. The PSi layer is formed by $\operatorname{SiH}_{\times}(x=1,2,3)$ bonds that remain on the surface. The PSi surface can oxidize spontaneously when it is kept in ambient air several times and the method continues until the overall surface is completely oxidized. Temperature and illumination increase the reaction rate, and change the properties of the PSi layer . Luminescence spectra exhibit a blue shift after oxidation of the surface. Fluorine is the main impurity in prepared PSi and its concentration can be controlled by the type of electrolyte used. The FTIR spectra of PSi samples are shown in Figure (6) FTIR spectra of Si bulk for (111), whereas Figure (7) FTIR shows a PSi sample with current density 10, 20 and $40 \mathrm{~mA} / \mathrm{cm}^{2}$ sequential at etching time $20 \mathrm{~min}$, HF 15\%, and HF 30\% for (100). Moreover, Figure (8) shows FTIR spectra for PSi sample with HF15\% at etching time 20min and current density $10 \mathrm{~mA} / \mathrm{cm}^{2}$ for (100) and (111) of transmittance peak IR and chemical [32]. 


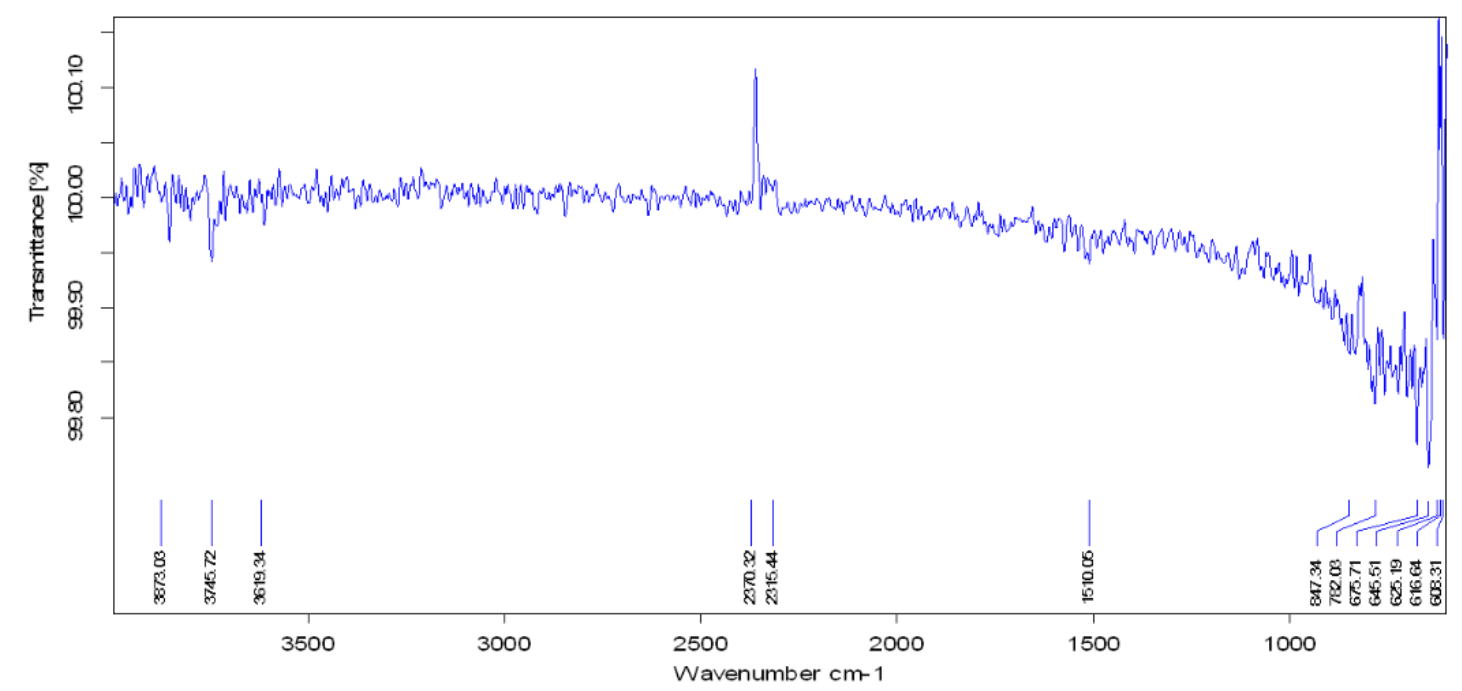

Figure 6: FTIR transmittance spectra Si-bulk (111)[33].
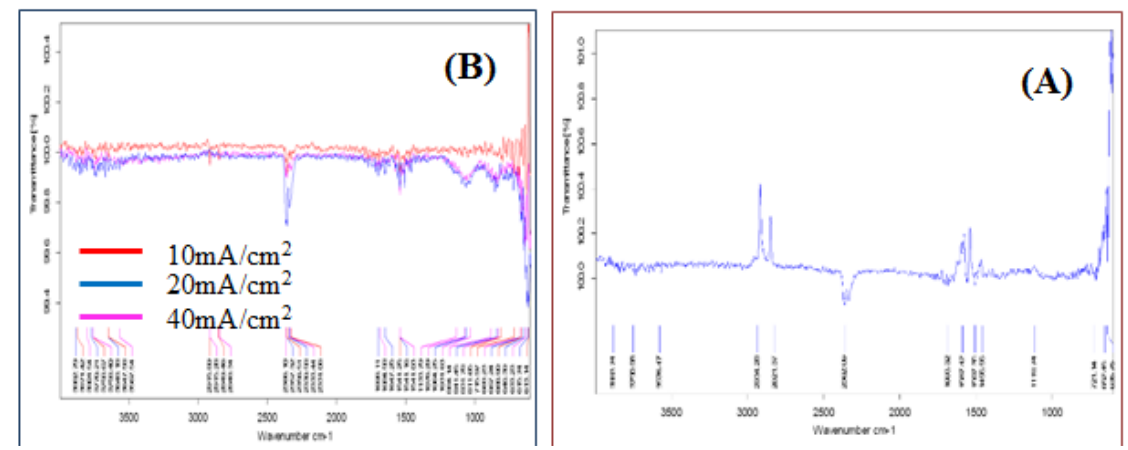

Figure 7 : FTIR transmittance spectral (100) (A) c-Si (B) 10, 20 \& $40 \mathrm{~mA} / \mathrm{cm}^{2}$, (C) $\mathrm{HF}_{\mathrm{c}} 15 \%$ and $30 \%[34]$.
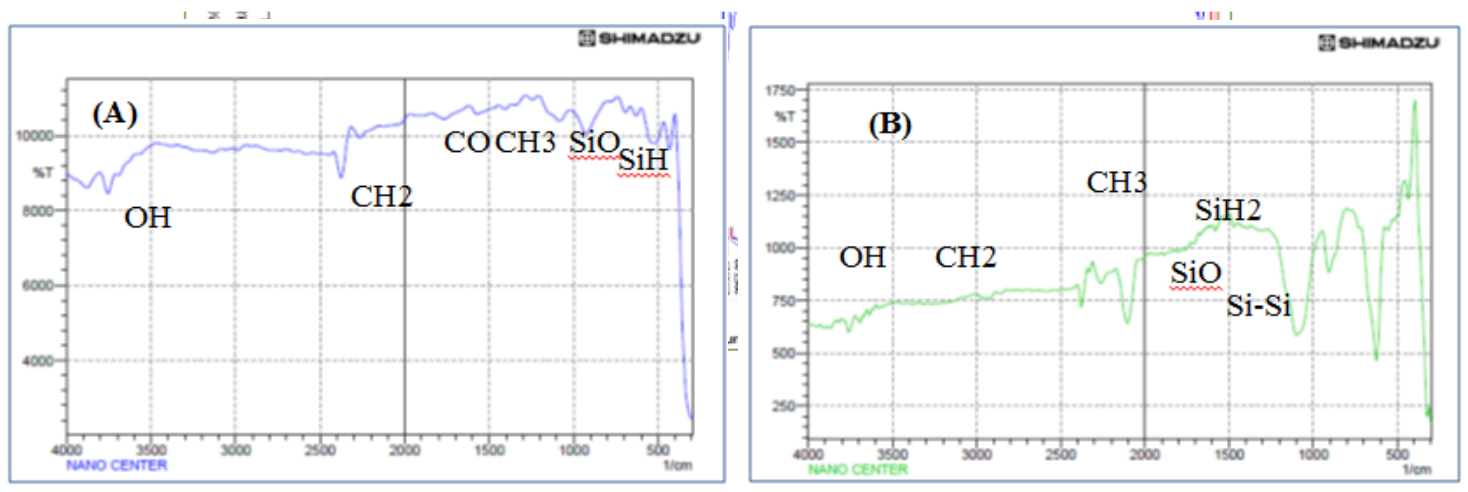

Figure 8: FTIR transmittance spectra of PS $10 \mathrm{~mA} / \mathrm{cm}^{2}, 20 \mathrm{~min}$ and $\mathrm{HF}_{\mathrm{c}} 15 \%$, (A) (100) and (B)

(111)[35].

\subsection{Physical properties of PSi}

\section{a. Structural properties}

It can be seen from Figure (9) that in bulk PSi the spectrum is broader than it is in bulk Si due to lattice mismatch in the PSi sample, which forms a strain regime. Moreover, it is evident that although the PSi layer remains crystalline, it showed a slight shift to smaller diffraction angles. Decreasing the crystalline size of PSi increases the energy gap[36]. The XRD spectra of silicon displays a clear sharp peak at $2 \theta=28.8^{\circ}$. It then becomes broad and varying full width at half maximum (FWHM) for different anodization current densities, as shown in Figure (9) and Tables (1) and (2), because of the formation of pores on the silicon surface . 

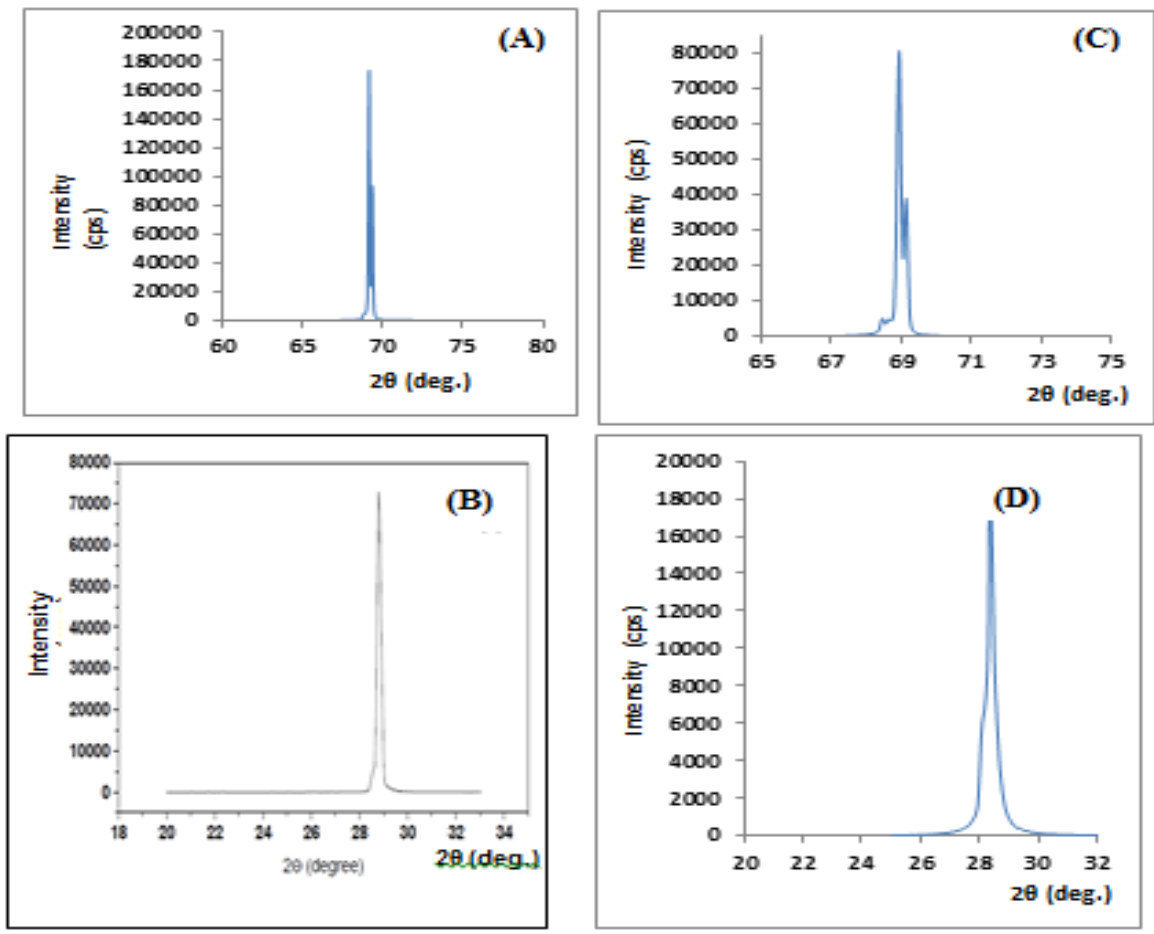

Figure 9: X-Ray diffraction pattern for (A) c-Si (100) (B) c-Si (111) (C) PS (100), (D) PSi (111) with etching time $20 \mathrm{~min}$, current density $30 \mathrm{~mA} / \mathrm{cm}^{2}$ and $\mathrm{HF}_{\mathrm{c}} 15 \%$ [37].

Table 1: (d) Inter-plane distance, (a) lattice constant, (L) crystallites size and energy gap for PSi with different orientation at $10 \mathrm{~mA} / \mathrm{cm}^{2}, 20 \mathrm{~min}$. and $\mathrm{HF}_{\mathrm{c}} 15 \%$.

\begin{tabular}{cccccccc}
\hline \hline Sample & $\begin{array}{c}\mathbf{2 \theta} \\
(\mathbf{d e g} .)\end{array}$ & $\mathbf{I}$ & hkl & $\begin{array}{c}\text { FWHM } \\
(\mathbf{d e g})\end{array}$ & $\begin{array}{c}\mathbf{d} \\
(\mathbf{n m})\end{array}$ & $\begin{array}{c}\mathbf{a} \\
(\mathbf{n m})\end{array}$ & $\begin{array}{c}\mathbf{L} \\
(\mathbf{n m})\end{array}$ \\
\hline \hline PS $\langle\mathbf{1 0 0}\rangle$ & 69.2041 & 81150 & 400 & 2.5250 & 0.2695 & 0.2695 & 3.82 \\
\hline PS $\langle\mathbf{1 1 1}\rangle$ & 28.4152 & 19462 & 101 & 2.2291 & 0.3138 & 0.5435 & 3.69 \\
\hline
\end{tabular}

Table 2 : Crystallite size obtained by means of the Scherrer equation for the PSi layer prepared under different current densities.

\begin{tabular}{cccc}
\hline \hline Etching time (min) & $\begin{array}{c}\text { Current density } \\
\left(\mathbf{m A} / \mathbf{c m}^{2}\right)\end{array}$ & $\begin{array}{c}\text { FWHM } \\
(\mathbf{d e g})\end{array}$ & Crystallite size (nm) \\
\hline \hline \multirow{2}{*}{$\mathbf{2 0}$} & 10 & 1.96560 & \\
\cline { 2 - 4 } & 20 & 2.06020 & 3.097 \\
\cline { 2 - 4 } & 40 & 2.27080 & 3.943 \\
\hline
\end{tabular}

\section{b. Surface properties of PSi}

The surface of PSi was investigated using atomic force microscopy (AFM), which analyses the display of the morphological properties at the nonmetric scale of the PSi layers. The morphology of the PSi samples that were prepared with etching times (5, 20 and $35 \mathrm{~min}$.), with different orientations (100), at constant current density $\left(30 \mathrm{~mA} / \mathrm{cm}^{2}\right)$ and constant $\mathrm{HF}$ construction (15\%) were characterized by the AFM technique. The images show that PSi has a sponge like structure and the porous width increased as the etching time increased, as noted in Table (3). As can be seen from Figure (10), the width and porosity of the pores increased with increasing etching time when HF concentration and current density were kept constant. This is attributed to the interaction of chemical 
dissolution of PSi layer in HF solution leading to PSi owing to its large surface area. In fact, chemical dissolution is responsible for the lower dissolution valence and the change of PSi density with depth. Moreover, the morphology of the PSi layer preparations changes with the etching time because the chemical reaction responsible for the etching processes is considered to be slow due to holes accumulation and consumption within the porous layer [38].
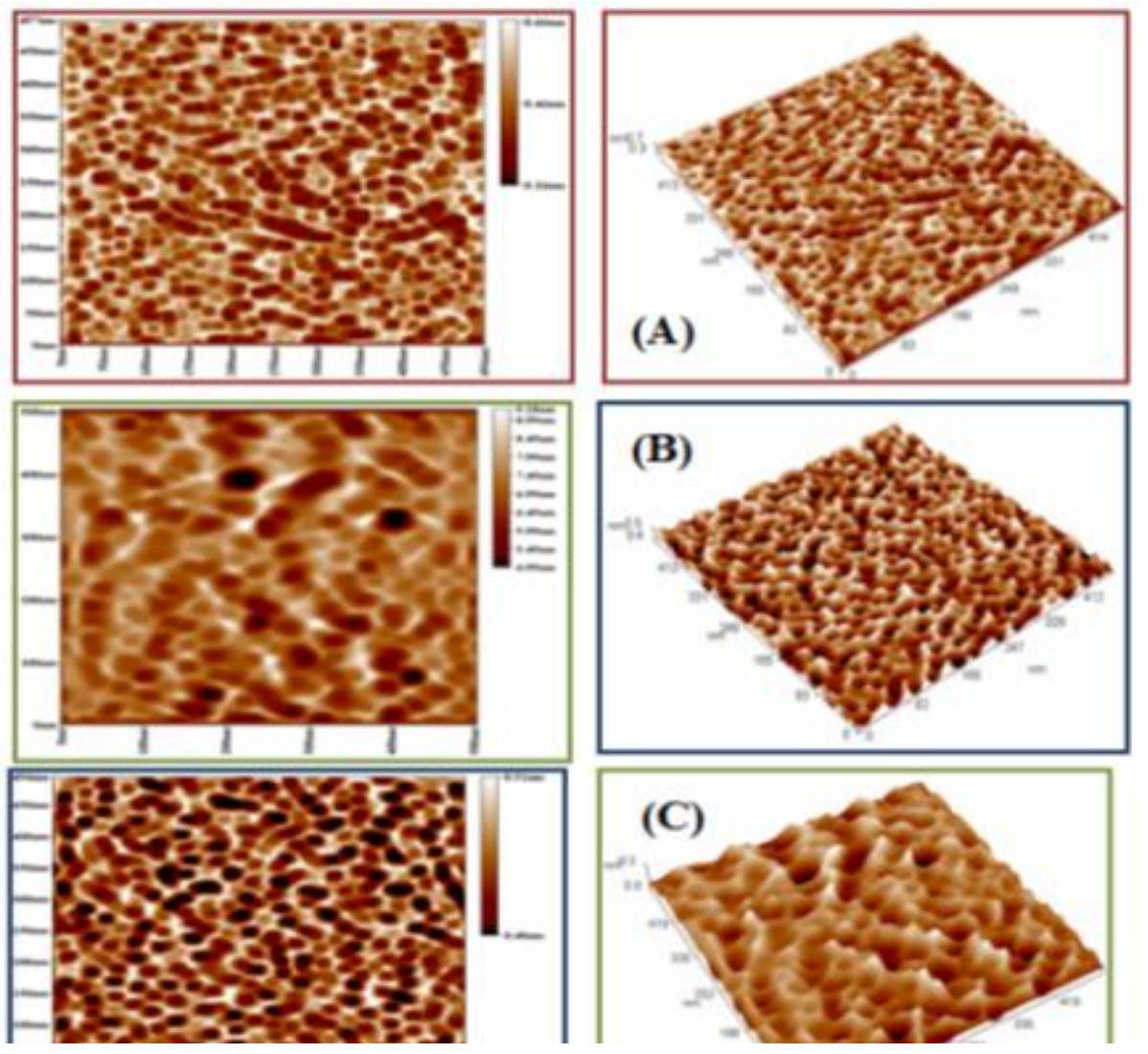

Figure 10: 2D and 3D AFM image for PSi with (A) 5 (B) 20 (C) $35 \mathrm{~min}$, at current density 30 $\mathrm{mA} / \mathrm{cm}^{2} \& \mathrm{HF}_{\mathrm{c}} \mathbf{1 5 \%}$, with silicon orientation (100)[39].

Table 3: Morphology features of PSi samples, at different etching times

\begin{tabular}{|c|c|c|c|}
\hline $\begin{array}{c}\text { Etching Time } \\
\text { (min) }\end{array}$ & "Orientation & $\begin{array}{c}\text { Average Diameter } \\
(\mathbf{n m})\end{array}$ & $\begin{array}{c}\text { Average Roughness } \\
(\mathbf{n m})\end{array}$ \\
\hline 5 & \multirow[t]{3}{*}{ (100) } & 21.48 & 0.245 \\
\hline 20 & & 18.88 & 0.725 \\
\hline 35 & & 28.18 & 0.563 \\
\hline 5 & \multirow[t]{3}{*}{ (111) } & 33.40 & 0.253 \\
\hline 20 & & 39.93 & 0.563 \\
\hline 35 & & 25.63 & 0.846 \\
\hline
\end{tabular}

With a longer etching time, the porosity decreases because of the new growth of pores that covers the old pores. This effect may be more important in low current density . It was expected that the etching illumination would play an important role in PSi properties. Therefore, a laser was used to etch the surface of PSi samples, which were prepared under $30 \mathrm{~mA} / \mathrm{cm}^{2}$ current density with a (24\%) HF acid concentration then illuminated by various etching wavelengths (Green, Red and IR) on n-type (1.5 - 4) $\Omega . c m$ for 20 minutes. It was found that the resultant porous structure, shown in Figure (11), has a pore like structure with different pore shapes and wall sizes. 

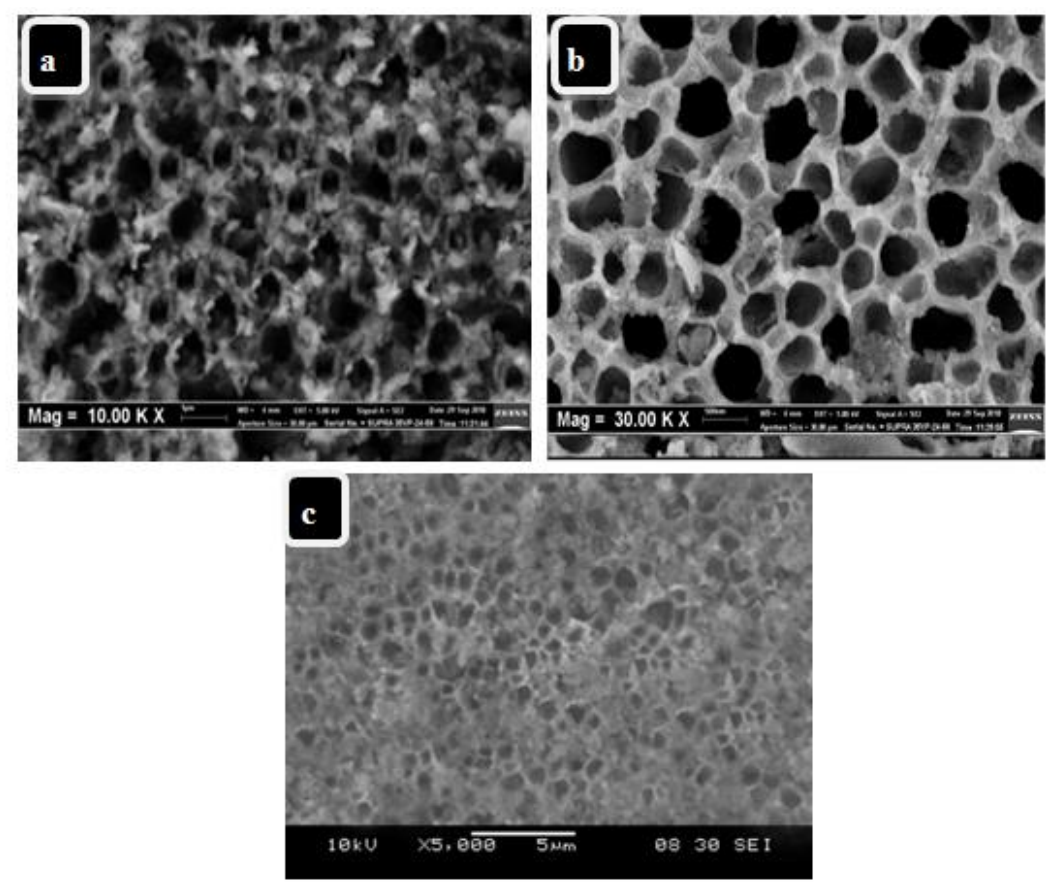

Figure 11: SEM images (nPSi) layers prepared at etching laser wavelength (a) Green, (b) Red and (c) I.R, at $30 \mathrm{~mA} / \mathrm{cm}^{2}$ for etching time $20 \mathrm{~min}[40]$.

Figure (11 a), presents tne morpnoıogical cnaracteristics or tne nrsi layer etcnea by a green laser. The SEM images show that the pores have a large diameter at sizes ranging from 1 to $0.2 \mu \mathrm{m}$. When a red laser is used for etching, a pore like structure can be observed, as shown in Figure 11(b), but with smaller sizes than those in Figure 11(a), ranging from 0.6 to $0.2 \mu \mathrm{m}$. Meanwhile, the infrared laser diode shows new morphological properties, (see Figure 11(c)), and the pore diameters range from $2-1 \mu \mathrm{m}$. Therefore, PSi of different sizes can be achieved using an etching laser at different wavelengths. However, the etching rate plays a key role and leads to non uniformity in pore diameter [41].

\section{Conclusion}

In this review, we attempted to establish a consistent understanding of the fabrication and characterization of PSi. We found that many important milestones have been achieved over the last few years. We also presented the main contributions of the chemical and physical properties of PSi devices. Experimental conditions can control the silicon layer with two significant sizes: the first is a region of microstructure silicon, and second is a region of nanostructure silicon with a large number of small pores. Finally, we predict that there will be further improvements in both fabrication and applications of PSi materials in the coming years.

\section{Acknowledgment}

The authors want to thank and appreciate the staff at the Department of Physics, College of Education for Pure Science, University of Mosul for providing research facilities required to complete this study

\section{References}

[1] Canham L., "Properties of Porous Silicon" $2^{\text {nd }}$ Ed., INSPEC, The Institution of Electrical Engineers, ,UK (1997).

[2] Canham L.T., Appl. Phy. Lett., 57(10) : 1046-1048 (1990).

[3] Lehman V., and Gosele, V., Appl. Phy. Lett., 58(856): 1233-1243 (1991).

[4] Tsai C. , Li K. H., Sarathy J. , Shin S. , Campbell J. C., and White J .M., Appl. Phy. Lett., 59(3):2814 (1993). 
[5] Halimaoui A., Springer -Verlag, 3(5): 33-50 (1995).

[6] Shigyo K. , Azumi K. and Seo, M. , J. of surf. analyst., 3( 2) : 502-510 (1997).

[7] Smith R. L., Collins S. D. , J. Appl. Phys. , 71(4): 1-22 (1997).

[8] Duttagupta S. P. , Fauchet P M , Ribes A C, Tiedje H F , Damaskinos S , Dixon T E , Brodie D E , and Kurinec S K., Solar Ener. Mater. and Solar Cells, 52: 271-283 (1998).

[9] Coulthard I. , Jiang Y. J. and Sham T. K. , J. of Porous Mater. , ;3 (7) :165-168 (2000).

[10] Ohmukai M., Yoshinori, N. and Yautsumi, H., Science and Technology of Adv. Mater.,; 2(4): $455-$ 557(2001).

[11] Foll H. , Christophersen, M. , Carstensen, J. , and Hasse, G., Mate. Sci. and Engin. R,; 280: 1-49 (2002).

[12] Jarimaviciute R. , Zvalioniene V. , Grigaliunas S. , and Guobiene A., Mater. Sci., 9(4): 317-320 (2003).

[13] Gaburro Z. , Daled, O. N. and Paves, L. , , "Porous Silicon", $2^{\text {nd }}$ Ed. Trento University, Italy (2004).

[14] Pap, A. E., M.Sc. Thesis , Faculty of Technology, Department of Electrical and Information Engineering, Oulu, University of Oulu(2005).

[15] Nichiporuk O. , Kaminski A., Lemiti M. , Fave A. , Litvinenko S. , Skryshevsky V. , Thin Sol. Films,; 2(5):248-251(2006).

[16] Chaoui R. and Abdelghani, M. ,Desalination, ; 209(4): 118-121 (2007).

[17] Kanungo J., Selegard L. , Vahlberg C. , Uvdal K. , Saha H. and Basu S., Bull. Mater. Sci., 33(6): 647-651 (2009).

[18] Granitzer P. and Rumpf K., Mater. , 3(4):943-998 (2010).

[19] Jian, H. , Sha, L. and Lin, C., Sci. China, 54(8): 1348-1356 (2016).

[20] Behzad K. , Yunus W. M. , Talib Z. A. , Zakaria A. , Bahrami A. and Shahriari, E. , J. of Mater., 5(3):157-168 (2017).

[21] Ghazwan Gh. Ali , Abdul Kahliq A. Sulaiman and Ivan B. Karomi , AIP Conf. Proc., 2034 (2018).

[22] Ghazwan Gh. Ali, Abdul Kahliq A.Sulamian and Marwan, Hafeedh Younus, Results in Phys., 14, 44-52, (2019)

[23] Ghazwan Gh. Ali , Ivan B. Karomi and Abdul Kahliq A. Sulaiman , Nucl. Inst. and Meth. in Phys. Rese. B , 468 : 23-27 (2020).

[24] Nel J., Ahmed M., Meyer W., Proc. SPIE. 11043, Fifth Confe. on Sensors,(2019).

[25] Becerra D. and Agarwal V., J. of Porous Mater, 16(2):191-195 (2016).

[26] Bisia O. , Ossicinib S. and Pavesi L., Sci. Rep., 38: 1-126 (2015).

[27] Ge M., Fang X., Rong J. and Zhou C., Mater., 24(42): 42201 (2013).

[28] Harraz F.A., Sens. and Actu. B: Chem., 202(3) :897-912 (2014).

[29] Haiping J., Xiaolin L., Junhua S., Xin Z., Nature Commun., 11(1474) (2020) .

[30] Mykola P., Valerii M. and Gloria G., Inter. J. of Mater. and Mech. Engin., 2(4):182-189 (2020).

[31] Naderi N. and Hashim M., Inte. J. Electro. Sci. , 7(2):1512-1518(2016).

[32] Ou W. and Zhao L., Inter. J. of Mater. and Mech. Engin., 1(1): 377-381 ( 2018).

[33] Massar A. and Fikhar M., Iraqi J. of Phy., 16 (37) :98-107 (2018).

[34] Gelloz B., Mentek R. and Koshlda N., J. of Solid Sci. and Tech., 3(5) : 83-88 (2014) .

[35] Kuen H., Hsien,W. and Chong L., Mater, 8(2): 5922-5932 (2015).

[36] Petr S. and Nikola S., Mater. , 15(3): 2333-41 (2019).

[37] Mogoda A. S. and Ahmad Y. H., Silicon, 11 :2837-2844 (2019).

[38] Russo L., Colangelo F. , Cioffi R., Rea I. and and De Stefano L., Mater., 4(1): 1023-1033 (2019).

[39] Sahoo M.K. and Kale P., Micr. and Meso. Mater., 289 :109619 (2019).

[40] Lara M. , Mile I. , Croat. Chem. Acta , 88(4): 437-444 (2015).

[41] Taeho K., Gary B. and Zhi-gang Sh., ACS Appl. Mater. Inter., 8(2): 30449-30457 (2016). 